\title{
Physiologic, Metabolic, and Muscle Fiber Type Characteristics of Musculus Uvulae in Sleep Apnea Hypopnea Syndrome and in Snorers
}

\author{
Frédéric Sériès, * Claude Côté, ${ }^{\ddagger}$ Jean-Aimé Simoneau, 5 Yves Gélinas, ${ }^{5}$ Sylvain St. Pierre," Jacques Leclerc, \\ Rénald Ferland,' and lsabelle Marc* \\ *Unité de Recherche, Centre de Pneumologie de l'Hôpital Laval; ${ }^{\ddagger}$ Laboratoire de Biorégulation Hormonale, Centre Hospitalier de \\ l'Université Laval; ${ }^{8}$ Laboratoire des Sciences de l'Activité Physique, Université Laval; "Département Otorhino Laryngologic, Hôpital \\ Laval; and 'Département Otorhino Laryngologic, Centre Hospitalier de l'Université Laval, Québec, Canada G1V 4G5
}

\begin{abstract}
Upper airway dilator muscles play an important role in the pathophysiology of sleep apnea hypopnea syndrome (SAHS). The mechanical and structural characteristics of these muscles remain unknown. The aim of this study was to compare the physiologic, metabolic, and fiber type characteristics of one upper airway dilator muscle (musculus uvulae, MU) in 11 SAHS and in seven nonapneic snorers. The different analyses were done on MU obtained during uvulo-palato-pharyngoplasty. Snorers and SAHS differed only in their apnea + hypopnea indices $(11.5 \pm 5.9$ and $34.2 \pm 14.6 / h$, respectively, mean \pm SD). Absolute twitch and tetanic tension production of $\mathrm{MU}$ was significantly greater in SAHS than in snorers while the fatigability index was similar in the two groups. Protein content and anaerobic enzyme activities of MU were significantly greater in SAHS than in snorers; no difference was observed for aerobic enzyme activities. The total muscle fiber cross-sectional area of MU was significantly higher in SAHS $\left(2.2 \pm 0.9 \mathrm{~mm}^{2}\right)$ than in snorers $\left(1.1 \pm 0.7 \mathrm{~mm}^{2}\right)$. The surface occupied by type IIA muscle fibers of MU was larger in SAHS $(2.00 \pm 0.96)$ than in snorers $\left(0.84 \pm 0.63 \mathrm{~mm}^{2}\right)$. We conclude that the capacity for tension production and the anaerobic metabolic activity of MU are greater in SAHS than in snorers. (J. Clin. Invest. 1995. 95:20-25.) Key words: upper airway collapsibility • upper airway dilator muscle $\bullet$ muscle fatigue, muscle fiber area $\cdot$ metabolic profile $\cdot$ human skeletal muscle
\end{abstract}

\section{Introduction}

The sleep apnea hypopnea syndrome (SAHS), is characterized by repetitive episodes of upper airway obstruction. The estimated prevalence of this syndrome in general population is $2 \%$

Address correspondence to Frédéric Sériès, MD, Centre de Pneumologie, Hopital Laval, 2725 Chemin Sainte Foy, Sainte Foy, (PQ), G1V 4G5, Canada. Phone: 418-656-4747; Fax: 418-656-4762 1994.

Received for publication 10 May 1994 and in revised form 22 August

1. Abbreviations used in this paper: EMG, electromyographic; MU, musculus uvulae; SAHS, sleep apnea hypopnea syndrome; UA, upper airway; UPPP, uvulo-palato-pharyngoplasty

J. Clin. Invest.

(c) The American Society for Clinical Investigation, Inc.

0021-9738/95/01/0020/06 $\$ 2.00$

Volume 95, January 1995, 20-25 in women and $4 \%$ in men (1). Upper airway (UA) collapsibility is increased in SAHS patients (2); this can be accounted for by several factors, such as a decrease in UA caliber (3), changes in mucosal characteristics (4), or changes in the lung-volume dependence of UA patency (5). UA collapse results from an imbalance between the forces that tend to occlude UA (negative transmural inspiratory pharyngeal gradient), and those that open it, such as the contraction of UA dilator muscles (6). These muscles are largely involved in the maintenance of UA patency: an increase in the activity of these muscles is associated with a decrease in UA resistance and collapsibility (7). Inversely, pharyngeal resistance and collapsibility increase with the decrease in UA muscles' electromyographic (EMG) activity (811 ). In SAHS, upper airway obstruction occurs at the nadir of the genioglossus muscle EMG activity (6).

The activity of UA dilator muscles partially determines the mechanical effects of their contraction $(12,13)$. The overall increase in the activity of these muscles can account for the increase in UA dilation (14) and the decrease in UA resistance (15) with increasing respiratory efforts. Since pharyngeal airways are not supported by rigid structures, UA muscles are important in determining their patency. Several reports suggest that UA closure is prevented by a hyperactivity of UA dilator muscles during wakefulness, and that the sleep-related loss of this neuromuscular compensation leads to the occurrence of obstructive breathing disorders $(16,17)$. The hyperactivity of UA muscles tends to compensate for the greater transmural pressure gradient and UA collapsibility.

Even if previously described data suggest that UA dilator muscles play an important role in the pathophysiology of SAHS, little is known on their contractile, histochemical, and biochemical properties. Previous studies have focused on the electromyographic activity of these muscles (16-18), but their mechanical and structural characteristics have not been studied. Since the effective pressure generated by the contraction of dilator muscles clearly depends on these characteristics, it is critical to determine how UA muscles respond to this compensatory hyperstimulation. Interestingly, Smirne et al. (19) recently found that the distribution of fiber types of a pharyngeal constrictor muscle is abnormal in snorers, suggesting that sleep-related breathing disturbances are associated with changes in UA muscles' characteristics. However, it is not known if mechanical failure in the form of excessive muscle fatigue could contribute to the occurrence of these breathing disorders. Musculus uvulae (MU) is responsible for the retraction of the uvula which is largely involved in the occurrence of nasopharyngeal closure. Our objective was to determine if significant differences exist between SAHS and nonapneic snorers in terms of contractile, histochemical, and biochemical characteristics of this UA muscle. 


\section{Methods}

Subjects. The patients included in the study ( $n=18,16$ males, age range $28-59 \mathrm{yr}$, body mass index: $30.6 \pm 5.5 \mathrm{~kg} / \mathrm{m}^{2}-$ mean \pm SD) underwent an uvulo-palato-pharyngoplasty (UPPP) in the participating institutions between February 1993 and March 1994. All subjects had a conventional polysomnographic study within $90 \mathrm{~d}$ before UPPP for treatment of snoring or SAHS. SAHS patients were not treated for their sleep-related breathing abnormalities, and no treatment was initiated between the sleep recording and the surgical procedure. All subjects had normal thyroid function tests and they weren't on any medication. The review board on human studies of our institution approved the experimental protocol and each subject gave his informed consent to participate in the study.

Sleep studies. Sleep studies were done according to standard polysomnographic techniques (20). Nasal and mouth airflow were measured with thermocouples (Grass Instruments Co., Quincy, $\mathrm{MA}$ ), $\mathrm{SaO}_{2}$ with an ear oximeter (Criticare 504; CSI, Waukesha, WI), electrocardiogram, thoracoabdominal movements by respiratory inductive plethysmography (Respitrace; Ambulatory Monitoring, Ardsley, NY) (21), and breathing sounds with two microphones placed at the head of the bed (22). All parameters were recorded on a 16-channel polygraph (model 78; Grass Instruments Co.) running at $10 \mathrm{~mm} / \mathrm{s}$.

Muscle sampling technique. MU was obtained during UPPP, which was done according to previously described techniques (23), except that the uvular tissue was excised first, without electro-cautery. No vasoactive agents were injected into the soft palate before or during the procedure. The uvular tissue was immediately dissected to isolate MU that was poured in ice cold Krebs-Ringer's buffer until contractile measurements were done within 30 min after surgery.

Measurements of contractile properties and fatigability. Isometric contractile properties were measured as previously described (24). Contractile properties were measured in vitro in a buffered physiological salt solution (Krebs-Ringer's) maintained at $35^{\circ} \mathrm{C}$ and supplemented with glucose $(2 \mathrm{mg} / \mathrm{ml})$ and curare $(20 \mu \mathrm{g} / \mathrm{ml})$. The $\mathrm{pH}$ of the bathing solution was stabilized at 7.4 by equilibration with a gas mixture of $95 \% \mathrm{O}_{2}-5 \% \mathrm{CO}_{2}$. Muscles were placed in a vertical bath and secured at each end with silk sutures. They were then stimulated with supramaximal pulses of $1.0 \mathrm{~ms}$ delivered through platinum electrodes. The output of the stimulator (model S-48; Grass Instrument Co.) was increased by a power amplifier (Stimu-Splitter II; Med-Lab Instruments, Loveland, $\mathrm{CO})$ such that the stimulation voltage in the bathing solution was $\sim 25 \mathrm{~V}$.

The first step of the protocol always consisted in finding the muscle optimal length $\left(\mathrm{L}_{0}\right)$, defined as the length at which maximal isometric twitch tension was produced. Muscles were then allowed to equilibrate with the incubation medium for $25 \mathrm{~min}$. At the end of the equilibration period, a twitch contraction was elicited, and the following measurements were obtained: maximum twitch tension $\left(P_{t}\right)$, contraction time, and half-relaxation time. Immediately after measurement of the twitch parameters, a force-frequency curve was obtained by stimulating the muscle for $700 \mathrm{~ms}$ at frequencies of $20,35,50,80$, and $100 \mathrm{~Hz}$. The muscles were given a 60 -s-rest between each tetanic contraction, and maximum tetanic tension $\left(P_{0}\right)$ was then recorded. A 5-min rest period followed the last tetanic contraction. The fatigue protocol was administered at the end of this resting period. It consisted in eliciting one 330 -ms tetanic contraction at $40 \mathrm{~Hz} / \mathrm{s}$ for $2 \mathrm{~min}$. A fatigability index corresponding to the percentage of initial tension at the end of the 2 min of intermittent stimulation was measured. The muscle length was measured before it was removed from the chamber. The sample was then blotted and weighed at the end of each experiment.

Fiber typing: and area measurements. Once physiological measurements were completed, all MU samples were sectioned in two pieces at about half of their length. One of these pieces was frozen in isopentane cooled at about $-160^{\circ} \mathrm{C}$ with liquid nitrogen for histochemical analyses, whereas the other half was frozen in liquid nitrogen for the biochemical analyses. These frozen samples were kept at $-70^{\circ} \mathrm{C}$ until processing.
For the histochemical analyses, $10 \mu \mathrm{m}$ thick transverse sections were cut from the middle region of the frozen MU sample in a cryostat maintained at $-20^{\circ} \mathrm{C}$. These sections were stained for myofibrillar ATPase activity according to the single-step ethanol-modified technique described by Mabuchi and Sreter (25) and commonly used in the laboratory of one investigator (26). Based on the myofibrillar ATPase properties under these conditions, the three major fiber types were identified from the same section and designated as type I, type IIA, and type IIB. The average cross-sectional area of as many fibers as possible, and belonging to each fiber type, was determined with the use of Mocha image analysis software (Jandel Scientific, San Raphael, CA) linked to a video camera (Sony, Tokyo Japan) fixed on an optical microscope (The Lietz Co., Overland Park, KS) from mATPase stained sections that were enlarged at a known magnification.

Biochemical analyses. Each sample was homogenized in an icecold enzyme extracting medium ( $0.1 \mathrm{M}$-Na-Phosphate, 2 mM EDTA, $\mathrm{pH} 7.2$ ) and sonicated five times for $5 \mathrm{~s}$ at $20 \mathrm{~W}$ with 85-s pauses in between (Sonicator; Sonic Power, Branson, Danbury, CT). The activity of phosphorylase, phosphofructokinase, citrate synthase, hexokinase, 3hydroxyacyl CoA dehydrogenase, GADPH, cytochrome oxidase, and creatine kinase were determined spectrophotometrically (spectrophotometer DU-65; Beckman Instruments Inc., Fullerton, CA) at $30^{\circ} \mathrm{C}$ $\left(25^{\circ} \mathrm{C}\right.$ for phosphorylase) according to previously described techniques (27-30).

Polysomnographic, physiological and biochemical analyses were done separately. Each investigator was blind to the results of the other analyses.

Data Analysis and Statistical Analysis. Polysomnographic recordings were manually interpreted. Sleep stages were defined in 30-s periods according to standard criteria (20). An apneic event was defined as a cessation of the oro-nasal flow for at least $10 \mathrm{~s}$, and an hypopnea as a $50 \%$ reduction in the sum signal of the Respitrace (Ambulatory Monitoring) associated with a desaturation $>4 \%$ and/or an arousal $(31,32)$. Breathing disorders were classified as obstructive when they were accompanied by a progressive increase in respiratory efforts. Snoring was defined as a spike in breathing sound intensity $>60$ decibels (21). The diagnosis of SAHS was retained in 11 patients whose apnea + hypopnea index was $>15 / \mathrm{h}(31)$. The other seven subjects were classified as snorers. Comparisons between the snorers and SAHS groups were done with a $t$-test on observation ranks (33) with a $P$ value $<0.05$ as a level of significance.

\section{Results}

Anthropometric characteristics were identical in snorers and SAHS (Table I). The presence of sleep fragmentation and the changes in sleep architecture observed in SAHS (Table I) are consistent with the presence of recurrent apneic and hypopneic events. Both groups had similar snoring indices. There was no significant difference in the percentage of total sleep time spent below $90 \% \mathrm{SaO}_{2}$, nor in the mean nocturnal $\mathrm{SaO}_{2}$ between SAHS and snorers. In the SAHS group, $73.0 \pm 10.6 \%$ of the apneic + hypopneic events were obstructive in type.

For technical reasons physiological measurements of the MU could be obtained in only nine SAHS patients. Contraction time and half-relaxation time were identical in the two groups (SAHS: $68.9 \pm 8.8 \mathrm{~ms}$ and $60^{\circ} \pm 10.4 \mathrm{~ms}$, snorers: $67.4 \pm 13.3 \mathrm{~ms}$ and $53.6 \pm 13.0 \mathrm{~ms}$, respectively). Both maximum twitch and tetanic absolute tensions were significantly greater in SAHS $(12.5 \pm 10.0 \mathrm{~g}$ and $57.9 \pm 51.1 \mathrm{~g})$ than in snorers $(6.4 \pm 9.2 \mathrm{~g}$ and $31.2 \pm 43.9 \mathrm{~g}$ ) (Fig. 1). These significant differences were still observed when the outlier value of each group is eliminated. To evaluate the influence of MU total muscle fiber cross-sectional area on the differences in tension production between the 
Table I. Morphometric, Sleep, and Sleep-Related Breathing Abnormalities Characteristic in Snorers and SAHS

\begin{tabular}{|c|c|c|}
\hline & $\begin{array}{l}\text { SAHS } \\
(n=11)\end{array}$ & $\begin{array}{l}\text { Snorers } \\
(n=7)\end{array}$ \\
\hline Men/Women & $10 / 1$ & $5 / 1$ \\
\hline Age & $48 \pm 11.0$ & $45 \pm 9.0$ \\
\hline Body mass index $\left(\mathrm{kg} / \mathrm{m}^{2}\right)$ & $31.2 \pm 5.4$ & $29.6 \pm 6.0$ \\
\hline TST (h) & $5.9 \pm 0.4$ & $6.2 \pm 0.8$ \\
\hline Stages I-II (Percent TST) & $69.7 \pm 9.2$ & $67.3 \pm 7.7$ \\
\hline Stages III-IV (Percent TST) & $12.1 \pm 5.0$ & $16.4 \pm 3.9 *$ \\
\hline Stage REM (Percent TST) & $18.2 \pm 6.0$ & $16.3 \pm 5.2^{*}$ \\
\hline Apnea-hypopnea index $(n / h)$ & $34.2 \pm 14.6$ & $11.5 \pm 5.9 *$ \\
\hline Arousal index $(n / \mathrm{h})$ & $27.2 \pm 13.8$ & $14.4 \pm 5.8^{*}$ \\
\hline Awake $\mathrm{SaO}_{2}(\%)$ & $96.7 \pm 1.7$ & $96.3 \pm 1.7$ \\
\hline Percent TST $<90 \% \mathrm{SaO}_{2}$ & $5.8 \pm 8.2$ & $1.3 \pm 1.6$ \\
\hline Mean nocturnal $\mathrm{SaO}_{2}(\%)$ & $93.5 \pm 3.4$ & $95.4 \pm 1.9$ \\
\hline
\end{tabular}

Mean \pm SD. ${ }^{*} P<0.05$ between the two groups. TST, total sleep time.

two groups, we also compared the values of $P_{0}$ normalized for this area. There was no difference in normalized $P_{0}$ between SAHS and snorers $\left(2.6 \pm 1.2 \mathrm{~kg} / \mathrm{cm}^{2}\right.$ and $2.2 \pm 1.4 \mathrm{~kg} / \mathrm{cm}^{2}$, respectively). There was no difference in the fatigability index between the two groups (SAHS: $24.6 \pm 10.8 \%$, snorers: $37.8 \pm 15.9 \%$ ) (Fig. 1).

The results of the histochemical analysis and of the MU protein content are reported in Table II. The protein content of MU was greater in SAHS than in snorers. For technical reasons, histochemical measurements could be obtained in only nine SAHS patients. The total number of muscle fibers and of type IIA fiber in MU were significantly higher in SAHS. There was no difference in the average fiber area of the different fiber types between SAHS and snorers. The total muscle fiber crosssectional area and the surface occupied by type IIA fibers were larger in SAHS than in snorers. None of the physiological and biochemical variables were correlated with anthropometric or sleep-related breathing disorders' characteristics.

Metabolic characteristics of MU for SAHS and snorers are given in Fig. 2. MU of SAHS had a significantly greater phosphofructolcinase, GADPH phosphorylase, and creatine kinase
Table II. Characteristics of $M U$

\begin{tabular}{|c|c|c|c|}
\hline & SAHS & Snorers & $\begin{array}{l}\text { SAHS/ } \\
\text { snorers }\end{array}$ \\
\hline & $n=9$ & $n=7$ & \\
\hline \multicolumn{4}{|l|}{ Total protein content } \\
\hline ( $\mu \mathrm{g} / \mathrm{mg}$ muscle) & $54.0 \pm 15.7$ & $35.9 \pm 10.2 *$ & 1.5 \\
\hline \multicolumn{4}{|c|}{ Total number of muscle } \\
\hline fibers $(n)$ & $1,320 \pm 353$ & $785 \pm 364 *$ & 1.7 \\
\hline \multicolumn{4}{|c|}{$\begin{array}{l}\text { Total number of each } \\
\text { muscle fiber type }(n)\end{array}$} \\
\hline Type I & $141 \pm 285$ & $119 \pm 116$ & 1.2 \\
\hline Type IIA & $1,090 \pm 430$ & $543 \pm 343 *$ & 2.0 \\
\hline Type IIB & $57 \pm 40$ & $79 \pm 48$ & 0.7 \\
\hline \multicolumn{4}{|l|}{ Fiber type area $\left(\mu \mathrm{m}^{2}\right)$} \\
\hline Type I & $1,224 \pm 664$ & $905 \pm 470$ & 1.3 \\
\hline Type IIA & $1,836 \pm 530$ & $1,586 \pm 424$ & 1.1 \\
\hline Type IIB & $1,777 \pm 992$ & $1,829 \pm 1,124$ & 0.9 \\
\hline \multicolumn{4}{|c|}{$\begin{array}{l}\text { Surface occupied by each } \\
\text { muscle fiber type }\left(\mathrm{mm}^{2}\right)\end{array}$} \\
\hline Type I & $0.11 \pm 0.10$ & $0.13 \pm 0.14$ & 0.8 \\
\hline Type IIA & $2.00 \pm 0.96$ & $0.84 \pm 0.63 *$ & 2.4 \\
\hline Type IIB & $0.11 \pm 0.08$ & $0.17 \pm 0.14$ & 0.6 \\
\hline \multicolumn{4}{|c|}{$\begin{array}{l}\text { Total muscle fiber cross- } \\
\text { sectional area }\left(\mathrm{mm}^{2}\right)\end{array}$} \\
\hline & $2.2 \pm 0.9$ & $1.1 \pm 0.7 *$ & 2.0 \\
\hline
\end{tabular}

Mean \pm SD. ${ }^{*} P<0.05$ between the two groups.

enzyme activities than snorers, suggesting an enhanced anaerobic metabolic profile. There was no significant difference in hexokinase $(2.0 \pm 0.7 \mathrm{U} / \mathrm{g}$ vs $1.8 \pm 0.6 \mathrm{U} / \mathrm{g})$ as well as in oxidative enzyme activities (citrate synthase: $7.9 \pm 3.0$ vs $7.5 \pm 1.7$ $\mathrm{U} / \mathrm{g}$ muscle, 3-hydroxyacyl CoA dehydrogenase: $8.9 \pm 2.0$ vs $8.3 \pm 1.8 \mathrm{U} / \mathrm{g}$ muscle, cytochrome oxidase: $2.7 \pm 1.6$ vs $1.8 \pm 0.8$ $\mathrm{U} / \mathrm{g}$ muscle) between SAHS and snorers.

\section{Discussion}

The major findings of the current study is that MU of SAHS has characteristics similar to those commonly found in resistive

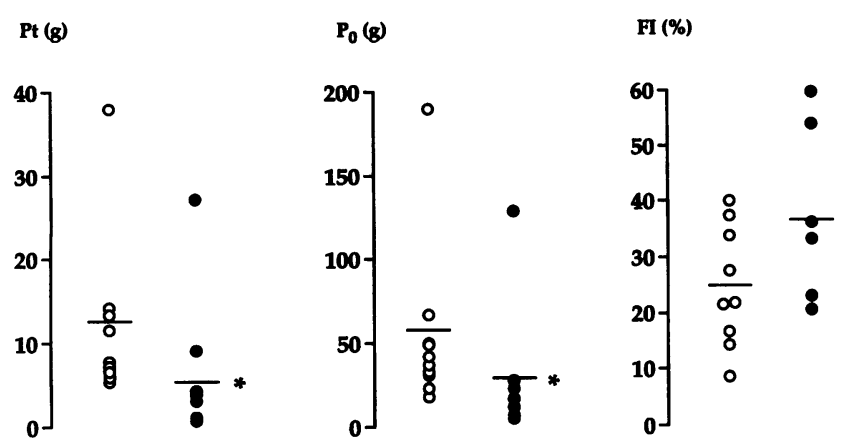

Figure 1. Individual and mean values of the maximum twitch $\left(\mathrm{P}_{\mathrm{t}}\right)$, tetanic $\left(\mathrm{P}_{0}\right)$ tensions, and of the fatigability index (FI) in SAHS $(O)$ and in snorers $(\bullet)$. For technical reasons, FI could be obtained in only six snorers. $* P<0.05$.

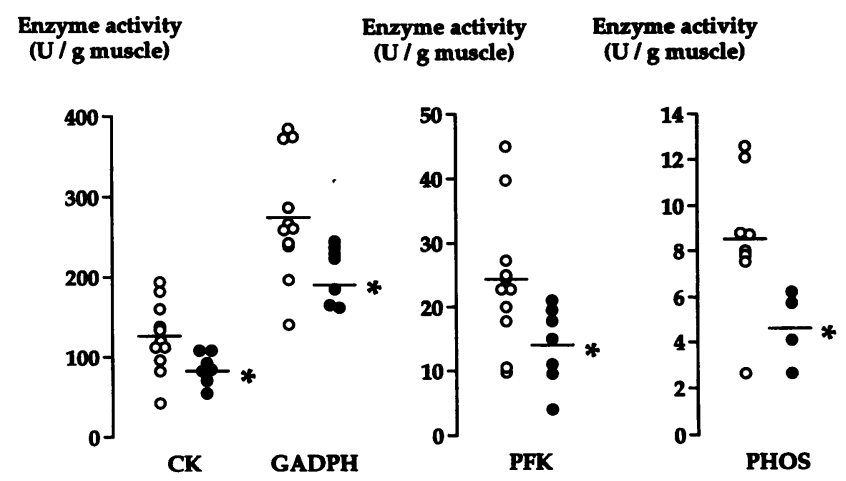

Figure 2. Individual and mean values of creative kinase, GADPH, phosphofructokinase, and phosphorylase enzyme activities in SAHS $(O)$ and in snorers $(\bullet) . \quad * P<0.05$. 
exercise-trained muscles, such as a higher force production and greater specific activities for anaerobic enzyme markers than in nonapneic snorers. We are not aware of any report on the pattern of EMG activity of MU during sleep and its correlation with the changes in pharyngeal resistance. However, several arguments strongly suggest that the activity of this muscle is similar to the one of other UA dilators: (a) UA closure mostly occurs at the nasopharyngeal level (34), (b) closure is associated with a hooking of the uvula and the soft palate (3), and (c) this hooking preceeds UA collapse (35). This reflects an overall increase in the activity of palato-pharyngeal muscles and particularly of MU whose function is to retract the uvula. The tensor veli palatini also contributes to maintain UA patency: like the genioglossus muscle, this muscle shows inspiratory activity at rest (36), and periodic fluctuations during sleep in SAHS, with a dramatic increase in its activity when ventilation resumes (37). Since MU, levator palatini, and tensor veli palatini demonstrate similar patterns of activity in response to negative airway pressure (38), it is reasonable to assume that the activity of MU is, like other UA dilator muscles, adapted to prevent UA closure, and that similar differences in muscle characteristics between snorers and SAHS are likely to exist in other UA dilators.

Snorers and SAHS clearly differed in their breathing characteristics during sleep, and snorers were considered as a control group. However, since sleep-induced increases in UA resistance can occur in snorers even in the absence of apneic or hypopneic events (39), we cannot infer that snorers represent a normal group. Our study population consisted of snorers and SAHS because they can benefit from UPPP and there is no other medical indication for this surgical procedure. It would be unethical to sample MU from healthy nonapneic nonsnorers because of the surgical procedure itself and the postsurgery rehabilitation requirements. MU morphology has been studied previously in "'normal"' subjects during autopsy (40). However, physiologic measurements need to be done on fresh tissues, and any delay in the measurements or anoxic tissular damages can alter muscular contractile properties. Therefore, the study of postmortem muscular samples obtained from nonsnorers could not be considered as representative of normal tissues. Furthermore, sleep and breathing characteristics cannot be obtained in an autopsy group. Since asymptomatic sleep-induced respiratory disorders are commonly observed in the general population (1), we strongly believe that it is particularly important to document the presence or absence of snoring and sleep-related breathing abnormalities for such a study.

Stauffer et al. (40) previously reported that uvula of SAHS patients contains a greater proportion of muscle and fat than those of normal subjects, but they were unable to find this difference between SAHS and snorers. Even if these two groups do not differ in their uvular morphological characteristics, our results demonstrate that the presence of sleep-related breathing abnormalities is associated with modifications in the physiological and metabolic profiles of the MU. The higher level of force production and anaerobic enzyme activities observed in the present study suggest that there is no myotonic or dystrophic disorder of UA muscles in SAHS.

As previously discussed, the force generated by the contraction of UA dilator muscles has a key role in the pathophysiology of SAHS. SAHS patients have more phasic genioglossus EMG activity than awake (16) and sleeping control subjects (18). This increased muscular activity can be seen as a compensatory mechanism to the increase in UA resistance and compliance (2, 41 ), as suggested by the reduction in EMG activity with the application of continuous positive pressure that normalizes the breathing pattern (42). In our study, the higher force developed by MU in SAHS than in snorers can be linked to the larger total muscle fiber cross-sectional area, as supported by the similar tetanic tensions developed by $\mathrm{MU}$ when $\mathrm{P}_{0}$ was normalized for total muscle fiber cross-sectional area. This increase in muscle force is consistent with the significantly higher decrease in UA resistance during $\mathrm{CO}_{2}$ rebreathing in SAHS than in normal subjects during wakefulness (15). We found a consistent greater activity in the different components of the anaerobic pathway in SAHS than in snorers: higher level of glycolytic (phosphofructokinase, GADPH), glycogenolytic enzyme activities (phosphorylase), and a greater ability to resynthesize ATP from creatine phosphate (creatine kinase). These differences in the physiological and metabolic profiles are similar to those observed after high intensity intermittent muscle training (43), and could be accounted for by recurrent transient muscle contractions in response to repetitive loading of UA in SAHS. According to the results of previous studies (44), the increase in the number of muscle fibers in SAHS may suggest that MU is faced up to a supramaximal resistive loading in these subjects. This is consistent with a physiological adaptive rise in MU activity to counterbalance the dramatic increase in the UA transmural pressure gradient observed in SAHS $(6,38)$. Smirne et al. (19) found that type I and IIB fibers were reduced with a proportional increase in type IIA fibers in the medium pharyngeal constrictor muscle between snorers and nonsnorers. We found that this increment in the composition in type IIA fibers is further enhanced between SAHS and snorers. This difference is compatible with an increase in type IIA fiber at the detriment of type IIB when human skeletal muscle is exposed to a chronic increase in contractile activity (45). Therefore, the histochemical differences in MU that we observed between apneic and nonapneic subjects are consistent with our physiologic and biochemical findings and strongly suggest that the UA muscles respond to an adaptive process such as an increase resistive loading. Using an animal model of sleep-related breathing disorders, Petrof et al. recently demonstrated that the differences in the immunohistochemical characteristics between bulldogs and control dogs were limited to the pharyngeal muscles with no differences in anterior tibialis characteristics between the two groups (46). This suggests that the changes in UA muscle characteristics in both studies are the consequences of the chronic load of UA and are not a general muscle phenomenon. It is interesting to note that there was no relationship between the physiological or biochemical characteristics and the frequency of sleep-related breathing abnormalities. This suggests that the recurrent increases in UA dilator muscle activity that occur during the night (6) cannot, by themselves, account for our findings. The genioglossus activity is significantly higher in SAHS than in nonapneic subjects during sleep (18) and also during wakefulness (16). We hypothesize that the physiological and metabolic changes observed in the present study are related to a 24-h intermittent training of UA muscles rather than exclusive nocturnal abnormalities.

Another explanation for our results refers to the influence of hypoxia on the metabolic pathways of skeletal muscle. Indeed, while the increase in muscle cross-sectional area is more likely due to a chronic increase in load applied to UA muscles, 
hypoxic conditions could also contribute to the development of metabolic adaptative responses. It is documented that chronic hypoxia induces an increase in skeletal muscle enzyme activities of glycolysis (27). Transient regular desaturation episodes were observed in SAHS, but it is not known if such $\mathrm{SaO}_{2}$ decreases have similar effects on metabolic pathways than chronic hypoxia. However, it can be hypothesized that in SAHS, recurrent episodes of hypoxemia every night could further enhance the anaerobic metabolism and, therefore, contribute to the observed increase in the anaerobic metabolic capacity. It is interesting that one SAHS patient whose sleep-related breathing disorders led to sleep fragmentation without a decrease in $\mathrm{SaO}_{2}$ had the lowest anaerobic enzyme activities (Fig. 2) of the group, but his $\mathrm{P}_{\mathrm{t}}$ and $\mathrm{P}_{0}$ absolute values corresponded to the mean values of the group ( $14.1 \mathrm{~g}$ and $49.5 \mathrm{~g}$, respectively). Therefore, high intensity intermittent muscle training and nocturnal hypoxemia may contribute separately to our findings. An important observation is that snorers and SAHS did not differ in terms of in vitro resistance to fatigue. The similarity in muscle fatigue was expected on the basis of a recent study that demonstrated a close relationship between citrate syntase activity level and muscle resistance to fatigue (47). It, therefore, appears very unlikely that the occurrence of obstructive breathing disorders could be explained by the presence of mechanical failure such as the development of muscle fatigue in mild to moderate SAHS.

From our results we conclude that, in SAHS, MU undergoes an adaptive process in response to chronic hyperstimulation and that sleep-related breathing disorders are not the consequence of muscle incompetence or fatigue. Further studies will have to determine if similar differences in muscle characteristics also exist in other UA dilators or in more severe SAHS patients. According to our findings, electrical stimulation during sleep (48) may not represent a logical approach in the treatment of SAHS, since it would further increase the muscle stress of an already hyperstimulated muscle and could decrease its performance and induce excessive muscle fatigue (49).

\section{Acknowledgments}

The authors thank S. Simard for statistical support and F. Péllégrini, N. Dupuis, A. Veilleux, C. McNicholl, and J. Beauregard for technical assistance.

This work was supported by l'Association Pulmonaire du Québec and Medical Research Council of Canada (grant no. MT-12151). Frédéric Sériès and Jean-Aimé Simoneau are scholars of the Fonds de la Recherche en Santé du Québec.

\section{References}

1. Young, T., M. Palta, J. Dempsey, J. Skatrud, S. Weber, and S. Badr. 1993. The occurrence of sleep-related breathing among middle-aged adults. $N$. Engl. $J$. Med. 328:1230-1235.

2. Gleadhill, I. C., A. R. Schwartz, N. Schubert, R. A. Wise, S. Permutt, and P. Smith. 1991. Upper airway collapsibility in snorers and in patients with obstructive hypopnea and apnea. Am. Rev. Respir. Dis. 143:1300-1303.

3. Suratt, P. M., P. Dee, R. L. Atkinson, P. Armstrong, and S. C. Wilhoit. 1983. Fluoroscopic and computed tomographic features of the pharyngeal airway in obstructive sleep apnea. Am. Rev. Respir. Dis. 127:487-492.

4. Wasicko, M. J., D. A. Hutt, R. A. Parisi, J. A. Neubauer, R. Mezrich, and N. H. Edelman. 1990. The role of vascular tone in the control of upper airway collapsibility. Am. Rev. Respir. Dis. 141:1569-1577.

5. Bradley, T. D., I. G. Brown, R. F. Grossman, N. Zamel, D. Martinez, E. Phillipson, and V. Hoffstein. 1986. Pharyngeal size in snorers, nonsnorers, and patients with obstructive sleep apnea. N. Engl. J. Med. 315:1327-1331.

6. Remmers, J. E., W. J. De Groot, E. K. Sauerland, and A. M. Anch. 1978.
Pathogenesis of upper airway occlusion during sleep. J. Appl. Physiol. 44:931938.

7. Oliven, A., M. Odeh, and N. Gavriely. 1989. Effects of hypercapnia on upper airway resistance and collapsibility in anesthetized dogs. Respir. Physiol. 75:29-38.

8. Hudgel, D. W., K. R. Chapman, and C. Hendricks. 1987. Changes in inspiratory electrical activity and upper airway resistance during periodic breathing induced by hypoxia during sleep. Am. Rev. Respir. Dis. 135:899-906.

9. Schwartz, A. R., P. L. Smith, R. A. Wise, I. Bankman, and S. Permutt. 1989. Effect of positive nasal pressure on upper airway pressure-flow relationship. J. Appl. Physiol. 66:1626-1634.

10. Wiegand, D. A., B. Latz, C. W. Zwillich, and L. Wiegand. 1990. Upper airway resistance and geniohyoid muscle activity in normal men during wakefulness and sleep. J. Appl. Physiol. 69:1252-1261.

11. Tangel, D. J., W. S. Mezzanotte, and D. P. White. 1991. Influence of sleep on tensor palatini EMG and upper airway resistance in normal men. J. Appl. Physiol. 70:2574-2581.

12. Fouke, J. M., J. P. Teeter, and K. P. Strohl. 1986. Pressure-volume behavior of the upper airway. J. Appl. Physiol. 61:912-918.

13. Leiter, J. C. 1992. Analysis of pharyngeal resistance and genioglossal EMG activity using a model of orifice flow. J. Appl. Physiol. 73:576-583.

14. Strohl, K. P., and J. M. Fouke. 1985. Dilating forces on the upper airway of anesthetized dogs. J. Appl. Physiol. 58:452-458.

15. Sériès, F., Y. Cormier, M. Desmeules, and J. La Forge. 1989. Effects of respiratory drive on upper airways in sleep apnea patients and normals. $J$. Appl. Physiol. 67:973-979.

16. Mezzanotte, W. S., D. J. Tangel, and D. P. White. 1992. Waking genioglossal electromyogram in sleep apnea patients versus normal controls (a neuromuscular compensation mechanism). J. Clin. Invest. 89:1571-1579.

17. Hendricks, J. C., B. J. Petrof, K. Panckeri, and A. I. Pack. 1993. Upper airway dilating muscle hyperactivity during non-rapid eye movement sleep in English bulldogs. Am. Rev. Respir. Dis. 148:185-194.

18. Suratt, P. M., R. F. McTier, and S. C. Wilhoit. 1988. Upper airway muscle activation is augmented in patients with obstructive sleep apnea compared with that in normal subjects. Am. Rev. Respir. Dis. 137:889-894.

19. Smirne, S., S. Iannaccone, L. Ferini-Strambi, M. Comola, E. Colombo, and R. Nemni. 1991. Muscle fiber type and habitual snoring. Lancet. 337:597599.

20. A. Rechtschaffen, and A. Kales, editors. 1968. A Manual of Standardized Terminology and Scoring System for Sleep Stages of Human Subjects. Brain Information Service/Brain Research Institute, University of California at Los Angeles. $55 \mathrm{pp}$.

21. Chadha, T. S., H. Watson, S. Birch, G. A. Jenouri, A. W. Schneider M. A. Cohn, and M. A. Sackner. 1982. Validation of respiratory inductive plethysmography using different calibration procedures. Am. Rev. Respir. Dis. 125:644649.

22. Sériès, F., I. Marc. 1993. Effects of protriptyline on snoring characteristics Chest. 104:14-18.

23. Fujita, S., W. Conway, F. Zorick, and J. Roth. 1981. Surgical correction of anatomical abnormalities in obstructive sleep apnea syndrome: uvulo-palatopharyngoplasty. Otolaryngol. Head. Neck. Surg. 89:923-934.

24. Frémont, P., H. Riverin, J. Frenette, P. A. Rogers, and C. Coté. 1991 Fatigue and recovery of rat soleus muscle are influenced by inhibition of an intracellular carbonic anhydrase isoform. Am. J. Physiol. 260:R615-R621.

25. Mabuchi K., and F. A. Sréter. 1980. Actomyosin ATPase. Quantitative measurement of activity in cryostat sections. Muscle \& Nerve. 3:227-232.

26. Simoneau, J.-A., and C. Bouchard. 1989. Human variation in skeletal muscle fiber-type proportion and enzyme activities. Am. J. Physiol. 257:E567E572.

27. Howald, H., D. Pette, J. A. Simoneau, A. Uber, H. Hoppeler, and P. Cerretelli. 1990. Effects of chronic hypoxia on muscle enzyme activities. Int. J. Sports. Med. 11:S10-S14.

28. Simoneau, J.-A., and D. Pette. 1988. Species-specific effects of chronic nerve stimulation upon tibialis anterior muscle in mouse, rat, guinea pig, and rabbit. Pflügers. Arch. Eur. J. Physiol. 412:86-92.

29. Gauthier, J. M., R. Thériault, G. Thériault, Y. Gélinas, and J.-A. Simoneau. 1992. Electrical stimulation-induced changes in skeletal muscle enzymes of men and women. Med. Sci. Sports. Exercise. 24:1252-1256.

30. Bradford, M. M. 1976. A rapid and sensitive method for quantification of microgram quantities of protein utilizing the principle of protein-dye binding Anal. Biochem. 72:248-254.

31. Gould, G. A., K. F. Whyte, G. B. Rhind, M. A. A. Airlie, J. R. Catterall, C. M. Shapiro, and N. Douglas. 1988. The sleep hypopnea syndrome. Am. Rev. Respir. Dis. 137:895-898.

32. American Sleep Disorders Association. 1992. EEG arousals: scoring rules and examples. Sleep. 15:174-183.

33. Montgomery, D. C. 1984. Design and Analysis of Experiments. John Wiley \& Sons, New York. 538 pp. 
34. Morrison, D. L., S. H. Launois, S. Isono, T. R. Feroah, W. A. Whitelaw, and J. E. Remmers. 1993. Pharyngeal narrowing and closing pressures in patients with obstructive sleep apnea. Am. Rev. Respir. Dis. 148:606-611.

35. Pépin, J. L., G. Ferreti, D. Veale, P. Romand, M. Coulomb, C. Brambilla, and P. A. Lévy. 1992. Somnofluoroscopy, computed tomography, and cephalometry in the assessment of the airway in obstructive sleep apnoea. Thorax. 47:150156.

36. Hairston, L. E., and E. K. Sauerland. 1981. Electromyography of the human palate: discharge patterns of the levator and tensor palatini. Electromyogr. Clin. Neurophysiol. 21:287-297.

37. Anch, A. M., J. E. Remmers, E. K. Sauerland, and W. J. Degroot. 1981. Oropharyngeal patency during waking and sleep in the Pickwickian syndrome: electromyographic activity of the tensor veli palatini. Electromyogr. Clin. Neurophysiol. 21:317-330.

38. Van Der Touw, T., N. O'Neill, A. Brancatisano, T. Amis, J. Wheatley, and L. A. Engel. 1994. Respiratory-related activity of soft palate muscles: augmentation by negative upper airway pressure. J. Appl. Physiol. 76:424-432.

39. Guilleminault, C., R. Stoohs, and S. Duncan. 1991. Snoring. I. Daytime sleepiness in regular heavy snorers. Chest. 99:40-48.

40. Stauffer, J. L., M. K. Buick, E. O. Bixler, F. E. Sharkey, A. B. Abt, E. K. Manders, A. Kales, R. J. Cadieux, J. D. Barry, and C. W. Zwillich. 1989. Morphology of the uvula in obstructive sleep apnea. Am. Rev. Respir. Dis. 140:724-728.

41. Anch, A. M., J. E. Remmers, and H. Bunce III. 1982. Supraglottic airway resistance in normal subjects and patients with occlusive sleep apnea. J. Appl. Physiol. 53:1158-1163.
42. Strohl, K. P., and S. Redline. 1986. Nasal CPAP therapy, upper airway muscle activation, and obstructive sleep apnea. Am. Rev. Respir. Dis. 134:555558.

43. Simoneau, J.-A., C. K. Allah, M. Giroux, M. R. Boulay, P. Lagassé, G. Thériault, and C. Bouchard. 1991. Metabolic plasticity of skeletal muscle in black and white males subjected to high-intensity intermittent training. Med. Sci. Sports. Exercise. 23:S149.

44. Gonyea, W. J., D. G. Sale, F. B. Goneya, and A. Milesky. 1986. Exercise induced increases in muscle fiber number. Eur. J. Appl. Physiol. Occup. Physiol. 55:137-141.

45. Andersen, P., and J. Henricksson. 1977. Training induced changes in the subgroups of human type II skeletal muscle fibers. Acta Physiol. Scand. 99:123125.

46. Petrof, B. J., A. I. Pack, A. M. Kelly, J. Eby, and J. C. Hendricks. 1994. Pharyngeal myopathy of loaded upper airway in dogs with sleep apnea. J. Appl. Physiol. 76:1746-1752.

47. Simoneau, J.-A., M. Kaufmann, and D. Pette. 1993. Asynchronous increase in oxidative capacity and resistance to fatigue of electrostimulated muscles of rat and rabbit. J. Physiol. (Lond.). 460:573-580.

48. Miki, H., W. Hida, T. Chonan, Y. Kikuchi, and T. Takishima. 1989. Effects of submental electrical stimulation during sleep on upper airway patency in patients with obstructive sleep apnea. Am. Rev. Respir. Dis. 140:1285-1289.

49. Schnall, R., S. G. Kelsen, and A. Oliven. 1993. Effects of chronic electrical stimulation on contractile and endurance properties of upper airway muscles in rats. Am. Rev. Respir. Dis. 147:A251. (Abstr.) 